КОНФЕРЕНЦИИ

Л. Н. Масленникова*, А. А. Собенин ${ }^{* *}$

$0 б$ итогах научно-практической конференции «0беспечение доступа к правосудию в уголовном судопроизводстве в условиях развития цифровых технологий»'

\begin{abstract}
Аннотация. В статье дается обзор прошедшей 22 июня 2021 г. в смешанном формате научно-практической конференции «Обеспечение доступа к правосудию в уголовном судопроизводстве в условиях развития цифровых технологий», организованной аппаратом уполномоченного по правам человека в Российской Федерации и Научно-образовательным центром по правам человека Московского государственного юридического университета имени О.Е. Кутафина (МГЮА). Работа конференции была посвящена актуальным вопросам обеспечения доступа к правосудию, возможностям цифровизации по преодолению ограничений в работе правоохранительных органов и судебной системы, обобщению опыта зарубежных государств и Российской Федерации по обеспечению прав участников уголовного судопроизводства. Конференция организована в рамках проекта Российского фонда фундаментальных исследований № 18-29-16018 «Концепция построения уголовного судопроизводства, обеспечивающего доступ к правосудию в условиях развития цифровых технологий».

Ключевые слова: конференция; обеспечение доступа к правосудию; права человека; цифровые технологии; цифровизация; уголовное судопроизводство; начальный этап уголовного судопроизводства; предварительное расследование; судебное разбирательство; проверочные стадии; правоохранительные органы; судебная система; суд присяжных.

Для цитирования: Масленникова Л. Н., Собенин А. А. Об итогах научно-практической конференции «Обеспечение доступа к правосудию в уголовном судопроизводстве в условиях развития цифровых технологий» // Актуальные проблемы российского права. - 2021. - Т. 16. - № 12. - C. 221-231. - DOI: 10.17803/19941471.2021.133.12.221-231.
\end{abstract}

1 Исследование выполнено при финансовой поддержке РФФИ в рамках научного проекта № 18-29-16018.

(C) Масленникова Л. Н., Собенин А. А., 2021

* Масленникова Лариса Николаевна, доктор юридических наук, профессор, профессор кафедры уголовнопроцессуального права Московского государственного юридического университета имени О.Е. Кутафина (МГЮА)

Садовая-Кудринская ул., д. 9, г. Москва, Россия, 125993

Inmaslennikova@msal.ru

** Собенин Андрей Анатольевич, кандидат юридических наук, доцент кафедры уголовно-процессуального права Московского государственного юридического университета имени О.Е. Кутафина (МГЮА)

Садовая-Кудринская ул., д. 9, г. Москва, Россия, 125993

aasobenin@msal.ru 


\title{
On the Outcomes of the Scientific and Practical Conference "Ensuring Access to Justice in Criminal Proceedings in the Context of Digital Technologies Development" ${ }^{2}$
}

\author{
Larisa N. Maslennikova, Dr. Sci. (Law), Professor, Professor, Department of Criminal Procedure Law, \\ Kutafin Moscow State Law University (MSAL) \\ ul. Sadovaya-Kudrinskaya, d. 9, Moscow, Russia, 125993 \\ Inmaslennikova@msal.ru
}

Andrey A. Sobenin, Cand. Sci. (Law), Associate Professor, Department of Criminal Procedure Law, Kutafin Moscow State Law University (MSAL)

ul. Sadovaya-Kudrinskaya, d. 9, Moscow, Russia, 125993

aasobenin@msal.ru

\begin{abstract}
The paper provides an overview of the scientific and practical conference "Ensuring Access to Justice in Criminal Proceedings in the Context of Digital Technologies Development" held on June 22, 2021 in a mixed format. It was organized by the Office of the Commissioner for Human Rights in the Russian Federation and the Scientific and Educational Center for Human Rights of Kutafin Moscow State Law University (MSAL). The conference was devoted to topical issues of ensuring access to justice, the possibilities of digitalization to overcome restrictions in the work of law enforcement agencies and the judicial system, generalizing the experience of foreign states and the Russian Federation in ensuring the rights of participants in criminal proceedings. The conference was organized within the framework of the project of the Russian Foundation for Basic Research No. 18-29-16018 "The concept of building criminal proceedings that provide access to justice in the context of the development of digital technologies."

Keywords: conference; ensuring access to justice; human rights; digital technologies; digitalization; criminal proceedings; initial stage of criminal proceedings; preliminary investigation; trial; verification stages; law enforcement agencies; judicial system; jury trial.

Cite as: Maslennikova LN, Sobenin AA. Ob itogakh nauchno-prakticheskoy konferentsii «Obespechenie dostupa k pravosudiyu v ugolovnom sudoproizvodstve v usloviyakh razvitiya tsifrovykh tekhnologiy» [On the Outcomes of the Scientific and Practical Conference "Ensuring Access to Justice in Criminal Proceedings in the Context of Digital Technologies Development"]. Aktual'nye problemy rossijskogo prava. 2021;16(12):221-231. DOI: 10.17803/19941471.2021.133.12.221-231. (In Russ., abstract in Eng.).
\end{abstract}

22 июня 2021 г. в Доме прав человека состоялась Всероссийская научнопрактическая конференция «Обеспечение доступа к правосудию в уголовном судопроизводстве в условиях развития цифровых технологий». Мероприятие прошло в гибридном формате с использованием технологии видеоконференции ${ }^{3}$.
Организаторами конференции выступили Научно-образовательный центр по правам человека Московского государственного юридического университета имени О.Е. Кутафина (МГЮА) и аппарат уполномоченного по правам человека в Российской Федерации.

В конференции приняли участие ученые из Москвы, Томска, Челябинска, Перми, региональ-

2 The reported study was funded by RFBR according to the research project № 18-29-16018.

3 Официальный сайт уполномоченного по правам человека в Российской Федерации. URL: http:// ombudsmanrf.org/news/novosti_upolnomochennogo/view/kruglyj_stol_posvjashhennyj_obespecheniju_ dostupa_k_pravosudiju_v_ugolovnom_sudoproizvodstve_v_uslovijakh_razvitija_cifrovykh_tekhnologij (дата обращения: 24.07.2021) ; официальный сайт Московского государственного юридического университета имени О.Е. Кутафина (МГЮА). URL: http://msal.ru/news/v-mgyua-proshla-nauchno-prakticheskayakonferentsiya-obespechenie-dostupa-k-pravosudiyu-v-ugolovnom (дата обращения: 24.07.2021). 
ные уполномоченные и сотрудники аппаратов (Республики Саха (Якутия), Рязанской, Калужской, Тульской, Владимирской, Московской областей, г. Москвы, Ханты-Мансийского автономного округа - Югры), представители Судебного департамента при Верховном Суде РФ, Министерства юстиции РФ, Министерства внутренних дел РФ, Следственного комитета РФ, представители Федеральной палаты адвокатов, представители некоммерческих правозащитных организаций.

С приветственным словом к участникам конференции обратились уполномоченный по правам человека в Российской Федерации доктор юридических наук, профессор Татьяна Николаевна Москалькова и проректор по научной работе Университета имени О.Е. Кутафина (МГЮА) доктор юридических наук, профессор Владимир Николаевич Синюков.

Модерировали конференцию руководитель Научно-образовательного центра по правам человека Университета имени О.Е. Кутафина (МГЮА) доктор юридических наук, профессор Игорь Геннадьевич Дудко и доктор юридических наук, профессор кафедры уголовнопроцессуального права Университета имени О.Е. Кутафина (МГЮА) Лариса Николаевна Масленникова.

В приветственном слове Татьяна Николаевна Москалькова подчеркнула особую важность и актуальность заявленной темы, которая направлена на обеспечение конституционного права на доступ к правосудию в уголовном судопроизводстве в условиях развития цифровых технологий.

Уполномоченный по правам человека в РФ обратила внимание на впечатляющие цифры: 44000 обращений поступило в ее ведомство за прошедший год, из которых более 11000 связаны с правами участников уголовного судопроизводства.

Граждане обращают внимание на то, что уголовный процесс является длительным, изнуряющим, но далеко не всегда справедливым. Сегодня на первое место выходит запрос на процессуальную справедливость, которая является гарантом обеспечения других прав. При столь остром вторжении в личную жизнь в процессе проведения следственных действий, нарушении ограничений на доступ к личным и семейным тайнам, ограничении свободы очень важно, чтобы гарантии соблюдения прав в уголовном судопроизводстве были максимально высоки.

На первом месте по числу обращений в аппарат уполномоченного по правам человека находятся заявления граждан, которые считают себя жертвами преступлений, но органы уголовного судопроизводства длительное время не признают их потерпевшими. Граждане высказывают обоснованные нарекания в адрес должностных лиц уголовной юстиции в связи с отсутствием действенных шагов по поиску подозреваемых, причинивших им физический, моральный или материальный вред.

Татьяна Николаевна обратила внимание собравшихся на пути развития электронного уголовного дела, цифрового формата уголовного судопроизводства. Цифровая трансформация уголовного судопроизводства обеспечивает быстроту и качество предварительного расследования, является дополнительной гарантией соблюдения разумных сроков, а также усиления прокурорского надзора и судебного контроля.

Владимир Николаевич Синюков в приветственном слове отметил, что Россия располагает достаточно высокой процессуальной культурой. Однако проблем остается очень много, особенно в сфере уголовного судопроизводства. Он указал на тенденцию к трансформации системы правосудия, в том числе в связи с развитием технологий, а следовательно, сменой глобальных моделей судопроизводства. Речь идет об упрощении в хорошем смысле, оптимизации, доступности правосудия. Все это является важной составляющей судебного процесса, так как от его эффективности зависит повышение эффективности реализации материального права или же, наоборот, усугубление последствий ошибок законотворчества.

Использование технологий дает нам шанс улучшить ситуацию с обеспечением доступа к правосудию, который мы должны непременно использовать. Следует уделить максимальное внимание технологическим аспектам, не забывая, однако, о том, что они в то же время несут в себе и потенциальные угрозы. 
Владимир Николаевич подчеркнул, что Университет имени О.Е. Кутафина (МГЮА) заинтересован в апробации результатов исследований в этой сфере. Также он выразил благодарность уполномоченному по правам человека за активные действия по развертыванию академической составляющей в интересах практической реализации защиты прав человека.

Профессор кафедры уголовно-процессуального права Университета имени О.Е. Кутафина (МГЮА) доктор юридических наук Лариса Николаевна Масленникова в своем выступлении «Актуальные проблемы доступа к правосудию в уголовном процессе и возможные пути их решения в условиях развития цифровых технологий» отметила несовершенство устройства уголовного процесса, что приводит к возникновению проблем доступа граждан к правосудию, которые обострились в период пандемии. Перевести досудебное производство в дистанционный формат в период пандемии оказалось сложно, производство по уголовным делам в ряде случаев останавливалось, несмотря на отсутствие подобных оснований в законе.

Профессор Масленникова выразила сожаление, что стадия возбуждения уголовного дела превратилась по сути в «квазирасследование», которое может длиться долгие месяцы и даже годы и заканчиваться отказом в возбуждении уголовного дела. Она отметила, что ряд ученых-процессуалистов предлагают отказаться от стадии возбуждения уголовного дела, как это сделали некоторые страны постсоветского пространства.

Особое внимание в своей речи спикер уделила возможностям, которые дает цифровая эпоха, и путям их реализации. Она считает, что современные представления о начале расследования уголовного дела устремлены к полной ликвидации стадии возбуждения уголовного дела. Перспективы связаны с электронной подачей сообщения о преступлении при наличии автоматизированной системы приема и передачи сообщений. Во многих странах это уже осуществляется именно таким образом. Искусственный интеллект будет помогать определять признаки конкретного преступления в сообщении. В уголовном судопроизводстве ряда стран уже сей- час предусмотрена подача жалоб в электронном виде, активно применяются видеотехнологии.

Лариса Николаевна обозначила проблему отсутствия цифровых платформ в уголовном судопроизводстве России, которые бы координировали действия государственных правоохранительных органов и заинтересованных лиц. Профессор Масленникова отметила, что процесс цифровизации является длительным, но неизбежным, любые предложения об автоматизации досудебного производства требуют законодательных изменений и дополнений. Для достижения этой цели необходимо будет объединить усилия специалистов в области уголовного процесса и цифровых технологий.

Доцент кафедры национального исследовательского Томского государственного университета кандидат юридических наук Татьяна Владимировна Трубникова представила совместный с заведующим кафедрой уголовного процесса, прокурорского надзора и правоохранительной деятельности доктором юридических наук Ольгой Ивановной Андреевой доклад на актуальную тему: «Уголовный процесс в эпоху постгенома и искусственного интеллекта: установление истины и (или) презумпция невиновности?".

Развивая тему справедливости процедуры правосудия, доцент Трубникова заявила, что правосудием можно считать лишь «справедливость в действии», когда процедура позволяет добиться справедливого результата и установления истины. Особый акцент в своем выступлении спикер сделала на важности соблюдения презумпции невиновности.

В современном мире появились новые технологии, позволяющие раскрывать преступления, в том числе давние. Но эти технологии содержат и очень большие опасности, а значит, следует поставить четкие границы их применения. Недопустимо обращаться с лицом, не признанным виновным, как с преступником.

Татьяна Владимировна подробно осветила проблему ДНК-регистрации, которая предусмотрена для лиц, осужденных за особо тяжкие преступления. Эти системы должны использоваться в практической деятельности, но необходим баланс между результатом их 
использования и неприкосновенностью личности. Хранение этой информации должно быть строго регламентировано. Лицо, в отношении которого вынесен оправдательный приговор или прекращено производство по уголовному делу по реабилитирующим основаниям, должно иметь возможность требования исключения этой информации из информационной базы. Также должен осуществляться независимый контроль для проверки оснований хранения этой информации. На данный момент законодательно отсутствуют инструменты, чтобы данные оправданного лица могли быть изъяты из информационной базы.

Заведующий кафедрой правоохранительной деятельности и национальной безопасности Южно-Уральского государственного университета доктор юридических наук Сергей Васильевич Зуев выступил с докладом «Допустимость применения цифровых технологий в современном уголовном судопроизводстве».

Профессор Зуев обратил внимание аудитории на тезис о разнонаправленности мнений по вопросу, насколько допустимо применение цифровых технологий в уголовном судопроизводстве. Превалирующая правовая доктрина «разрешено все, что прямо предусмотрено в законе». Однако практика нарабатывает новый подход, так называемый демократично-запретительный метод: если что-то прямо не запрещено законом, это можно использовать.

В этой связи ученый предлагает ряд правил для уголовного судопроизводства в цифровой трансформации. Первое правило определяет дистанционный формат уголовного судопроизводства. Второе правило: бумажный документооборот не может рассматриваться как единственно возможный вариант фиксации процессуальных действий, видеофиксация так же значима и информативна.

Следующее правило касается электронной формы фиксации заявлений о совершении преступлений. Здесь следует разделять электронную фиксацию и электронное заявление. Фиксироваться может, например, явка с повинной как форма электронного заявления или рапорт в электронном виде. А в перспективе обращение должно повлечь за собой обязательную элек- тронную фиксацию - непосредственно гражданином либо специальным сотрудником.

Четвертое правило касается электронных доказательств. Под этим ученый-процессуалист подразумевает рассмотрение документов в цифровом формате наравне с традиционными. Этот вопрос необходимо закрепить на законодательном уровне.

Последнее правило касается общего развития и предполагает оказание услуг гражданам посредством цифровой сети: ознакомление граждан с уголовно-процессуальными документами в электронном виде, возможность обжалования процессуальных решений. Конечно же, требуется интернет-платформа, которая объединит все возможности, связанные с уголовными делами.

Профессор кафедры уголовного процесса и криминалистики Пермского государственного национального исследовательского университета доктор юридических наук Павел Сысоевич Пастухов в выступлении «Идентификация и аутентификация участников при осуществлении дистанционного судопроизводства» обратил внимание на интересную аналогию. Пандемия толкнула нас к неизбежному, вынужденному электронному взаимодействию, но оказалось, что такое удаленное взаимодействие - не только не сложно, но и очень удобно. Современные возможности идентификации и аутентификации минимизируют ошибки в установлении личности. Раз уж мы можем себе позволить коммуницировать удаленным способом, почему бы не перенести это в уголовный процесс и не облегчить этим задачу всем участникам?

Профессор Пастухов считает, что модернизацию уголовного судопроизводства необходимо рассматривать вкупе с криминалистикой и информационными технологиями с прицелом на электронный документооборот. Запоздалое внедрение электронного документооборота отбрасывает страну далеко назад. Если раньше идентификатором у человека был только паспорт, то теперь выделяют 28 идентификаторов, их набор формирует цифровой профиль - так называемый биометрический профиль личности. Завершая речь, профессор Пастухов под- 
черкнул, что с технологической точки зрения нет никакой проблемы в идентификации личности.

Уполномоченный по правам человека в Рязанской области Наталья Леонидовна Епихина заявила, что процесс возбуждения уголовного дела зачастую длительный, изнурительный и не всегда справедливый. Очень часто потерпевшим невозможно добиться возбуждения уголовного дела.

Наталья Леонидовна выразила приверженность позиции, что создание специального портала для подачи заявлений в электронном виде может заметно улучшить положение на стадии возбуждения уголовного дела. Особенно это важно для маломобильных граждан, для заявителей о преступлениях, связанных с домашним насилием. Личное обращение в правоохранительные органы - всегда стресс для человека, в этой связи необходима возможность подачи заявления в цифровом формате. Ведение же уголовного дела в электронном виде обеспечивает более короткие сроки расследования, удобство для участников уголовного судопроизводства, прозрачность совершения процессуальных действий и принимаемых решений.

Профессор кафедры уголовно-процессуального права Университета имени О.Е. Кутафина (МГЮА) доктор юридических наук Людмила Мильтоновна Володина в рамках доклада на тему «Право на доступ к правосудию в условиях развития цифровых технологий: проблемы уголовного судопроизводства» начала выступление с важного тезиса о том, что свобода доступа к правосудию означает прежде всего возможность обеспечения судебной защиты. Указанная проблема не является сегодня новой, ежегодно в рамках осуществления прокурорского надзора обнаруживается более 4,5 млн нарушений, их них 3,5 млн - на стадии возбуждения уголовного дела.

В условиях пандемии стало понятно, что объективная реальность требует особой регламентации процессуального режима в чрезвычайной ситуации. Применение электронных технологий в сфере уголовного делопроизводства связано с определенными сложностями. В рамках обсуждения проблем, касающихся доступа к правосудию, сейчас высказываются различные предложения, но по ряду вопросов нет четкого понимания механизмов внедрения новых технологий в досудебное делопроизводство. Для решения этих вопросов пока руководствуются ведомственными инструкциями, что влечет за собой административный произвол.

Профессор Володина предложила ряд алгоритмов ведения начального этапа уголовного делопроизводства в электронном формате. Первым шагом должна стать регистрация поступившего сообщения в едином порядке с помощью специальной компьютерной программы; вторым шагом - решение следователя о принятии заявления и допущении дела к производству; третьим шагом стал бы сбор материалов о причастности конкретного лица к преступлению. Спикер также отметила, что в числе приоритетных задач должно быть принятие мер по быстрому устранению последствий преступления.

Профессор кафедры управления органами расследования преступлений Академии управления МВД России доктор юридических наук Борис Яковлевич Гаврилов в сообщении «Влияние цифровых технологий на обеспечение прав участников уголовного процесса на доступ к правосудию» акцентировал внимание слушателей на том, что проблема обеспечения доступа к правосудию давно уже является широко обсуждаемой.

Нерешенность указанной проблемы привела к существенному падению эффективности уголовного правосудия. Спикер привел интересные данные статистики. Сегодня порядка пяти миллионов граждан не получают доступа к правосудию, в том числе при необоснованных отказах в возбуждении уголовного дела в случаях, когда расследование необходимо начинать незамедлительно.

К сожалению, у многих устоялось мнение о том, что институт возбуждения уголовного дела является сегодня неким барьером, защищающим от необоснованного привлечения граждан к уголовной ответственности.

В настоящий момент около 20 тыс. сотрудников полиции только проверяют сообщения о преступлении и готовят отказные материалы, а 10 тыс. прокуроров занимаются отменой этих незаконных постановлений. 
Около 700 тыс. преступлений, по сути, на сегодняшний день остались нераскрытыми. Количество возбужденных уголовных дел за последние годы сократилось примерно на $15 \%$, дела эти перешли в категорию отказных. В последние тридцать лет принимались некоторые меры по наведению порядка, но носили они исключительно административный характер.

Начальник отдела методического обеспечения судов общей юрисдикции Главного управления организационно-правового обеспечения деятельности судов Судебного департамента при Верховном Суде РФ Лариса Михайловна Водопьянова в докладе «Расширение возможности применения дистанционного участия в уголовном судопроизводстве» отметила, что сегодня актуализируется необходимость принятия мер по повышению доступности правосудия с использованием современных цифровых технологий. Это и электронный документооборот между участниками судопроизводства и судом, и возможности применения видеоконференц-связи, и дистанционное участие в судебном процессе. По мнению докладчика, актуальной становится проблема установления личности участника судебного заседания, в том числе через единую систему идентификации, которая включает сбор и обработку данных.

Спикер напомнила о существовании законопроекта, касающегося изменений в уголовном процессе в связи с цифровизацией. Данным нормативным актом предложено расширить применение имеющихся цифровых систем, а также решить вопрос о допустимости участия в судебном заседании с помощью личного компьютера, смартфона, планшета и других средств связи.

Актуальным вопросом Лариса Михайловна считает обеспечение гарантий соблюдения условий, позволяющих производить защищенное соединение участников видеоконференции при выполнении следственных и процессуальных действий. Немаловажным фактом в осуществлении уголовного правосудия является то, что сегодня в каждом суде достаточно залов, оборудованных видео-конференц-связью, что, безусловно, влечет дополнительные затраты из федерального бюджета.
Старший научный сотрудник отдела научного обеспечения международного сотрудничества прокуратуры и сравнительного правоведения Университета прокуратуры Российской Федерации кандидат юридических наук Ирина Валерьевна Чащина представила доклад "Опыт депонирования показаний потерпевшего в государствах - участниках СНГ и возможность его использования в Российской Федерации».

По мнению спикера, использование цифровых технологий при допросе потерпевших и свидетелей способно ускорить проведение судебных процедур, повысить их качество и прозрачность, поскольку случаи уклонения участников процесса от явки в судебное заседание приводят к затягиванию рассмотрения дела.

Докладчиком предложено на стадии предварительного расследования проводить очные ставки в дистанционном формате. Возможность проведения дистанционного производства по уголовным делам в ходе предварительного расследования предусмотрена во многих постсоветских республиках.

Использование видео-конференц-связи в уголовном судопроизводстве, по мнению выступающего, является перспективным направлением. Необходимо закрепить возможность допроса потерпевшего или свидетеля по видеосвязи и возможность депонирования их показаний, так как это позволяет обеспечить соблюдение разумных сроков уголовного судопроизводства.

Доцент кафедры уголовного процессуального права Университета имени О.Е. Кутафина (МГЮА) кандидат юридических наук Ксения Андреевна Таболина в своем выступлении «Обеспечение прокурором доступа к правосудию в уголовном судопроизводстве в условиях развития цифровых технологий» акцентировала внимание на роли прокурора в обеспечении доступа к правосудию в цифровую эпоху.

В целом обязанность обеспечить доступ к правосудию возложена на государство. Досудебное производство призвано гарантировать этот доступ. Роль прокурора в обеспечении доступа к правосудию четко не определена в законодательстве, что привело к снижению его роли в этом процессе. 
Большинство нарушений (более 70 \%) выявляется прокурорами именно на этапе проверки сообщения о преступлении. За последние годы сократилось число постановлений прокуроров, которыми отменены процессуальные решения об отказе в возбуждении уголовного дела, что, безусловно, является положительной тенденцией. Однако на 30 \% возросло число жалоб на отказ в возбуждении уголовного дела. В настоящее время прокурор лишен полномочий в достаточной мере реагировать на выявленные им нарушения.

Что касается процессуального статуса прокурора, конечно, у него должна быть главенствующая роль по осуществлению уголовного преследования. Этот статус не должен предполагать возможность обжалования его решений со стороны органов уголовного преследования.

В завершении выступления Ксения Андреевна подчеркнула, что в условиях цифровизации уголовного производства обеспечение доступа к правосудию приобретает особое значение. Генеральная прокуратура РФ уже утвердила концепцию цифровой трансформации своих органов, в которой предложено создание онлайн-платформы по работе в цифровом формате с материалами уголовного дела. Вместе с тем спикер считает целесообразным присоединить такую платформу к единой государственной автоматизированной системе "Доступ к правосудию», которая требует тщательнейшей проработки.

Выступления продолжила член Совета Федеральной адвокатской палаты Российской Федерации, советник адвокатского бюро «Егоров, Пугинский, Афанасьев и партнеры» Елена Георгиевна Авакян.

В первую очередь она заявила, что идея создания единой платформы для ведения уголовных дел сама по себе не является новой. К сожалению, сейчас наблюдается огромное цифровое неравенство между участниками судопроизводства: судом, органами дознания и адвокатурой. В части цифровой трансформации адвокатура довольно быстро продвигается вперед. При этом органы предварительного расследования во многом сегодня еще не автоматизированы.

Далее спикер отметила, какие нововведения в результате цифровизации уголовного процесса считает наиболее желательными. Во-первых, это доступ в СИзО адвокатов по электронным ордерам, во-вторых, введение электронных паспортов адвокатов с возможностью привязки к ним электронных ордеров, в-третьих, возможность коммуникации со своими доверителями посредством видео-конференц-связи.

Кроме того, Елена Георгиевна назвала актуальными вопросы о взаимодействии цифрового судопроизводства с порталом «Госуслуги» и о системе идентификации и аутентификации, а также необходимость появления на портале «Госуслуги» статуса адвоката.

Докладчик рассказала, что Европейский Союз сегодня рассматривает возможность принятия ряда запретительных мер, связанных с использованием искусственного интеллекта в судопроизводстве, что является важнейшим условием сохранения конфиденциальности и приватности. Участник судопроизводства должен чувствовать себя в безопасности, а это недостижимо при тотальном мониторинге всех действий физических лиц. Невозможность использования результатов деятельности искусственного интеллекта - это условие сохранения спокойствия в обществе.

Доцент кафедры уголовно-процессуального права Университета имени О.Е. Кутафина (МГЮА) кандидат юридических наук Татьяна Юрьевна Вилкова в докладе «Право на доступ к правосудию в условиях развития цифровых технологий: проблемы уголовного судопроизводства» затронула проблемы доступа к правосудию не только в досудебном производстве, как большинство предыдущих спикеров, а на всех судебных стадиях, включая проверочные.

Татьяна Юрьевна поддержала тезис о необходимости цифровизации уголовного судопроизводства, который актуализировался в связи с пандемией. Уже понятно, что человечеству не удастся быстро преодолеть эту проблему, а в условиях пандемии качество судебного разбирательства наиболее пострадало и продолжает страдать. Сегодня непосредственное участие в судебном процессе стало ограниченным.

Самым сложным компонентом в этой связи спикер назвала суд с участием присяжных, который предполагает нахождение большого 
количества людей в едином пространстве, в помещении. Чтобы допустить участие нескольких десятков людей в судебном заседании, требуется комплекс мер, включая санитарно-гигиенические, аренду очень крупных помещений и т.д. Здесь, безусловно, встает вопрос о дистанционном участии присяжных заседателей.

Опасения у докладчицы вызывает тот факт, что на фоне пандемии в различных странах появились законопроекты о «сворачивании» суда присяжных. Предлагаются конкретные шаги: от сокращения количества дел, рассматриваемых с участием присяжных, до передачи всех дел профессиональному составу суда. И такое ограничение наиболее демократичной формы отправления правосудия, конечно, очень опасно. В этой ситуации целесообразно использовать возможности цифровизации уголовного судопроизводства.

Поводя итог выступлению, Татьяна Юрьевна рекомендовала разработку федерального закона об электронном правосудии, который установит условия, основания, порядок цифровизации, с тем чтобы был соблюден баланс интересов всех участников уголовного судопроизводства.

Доцент кафедры уголовно-процессуального права Университета имени О.Е. Кутафина (МГЮА) кандидат юридических наук Андрей Анатольевич Собенин в докладе «Обеспечение доступа к правосудию органами уголовной юстиции государств - членов Совета Европы в условиях развития цифровых технологий» напомнил, что в рамках Европейского Союза предпринимаются масштабные действия, направленные на урегулирование использования искусственного интеллекта в судебном процессе. Любой алгоритм там подчиняется базовым принципам правосудия. В Российской Федерации использование искусственного интеллекта в практической деятельности, в том числе в уголовном судопроизводстве, осуществляется без необходимого законодательного регулирования.

Международная конференция «На пути к электронному правосудию, ориентированному на людей», организованная Министерством юстиции в Совете Европейского Союза под председательством Португалии, прошла с
26 по 27 апреля 2021 г. в Лиссабоне. Конференция позволила обменяться знаниями и опытом, передовой практикой, озвучить примеры того, как резко ускорился процесс внедрения цифровых инноваций во время пандемии COVID-19 и как технологии и услуги были разработаны и адаптированы для удовлетворения потребностей граждан и юридических сообществ в судопроизводстве. Вспышка пандемии COVID-19 создала серьезные проблемы для функционирования правосудия, продемонстрировав слабые стороны технологически менее развитых государств и подтвердив важность цифровых технологий для обеспечения непрерывного доступа к правосудию и необходимость повышения его устойчивости.

На портале государственных услуг РФ анонсировано создание суперсервиса «Подача заявления в правоохранительные органы». На 2021 г. в качестве эксперимента запланирован прием сообщений о преступлениях в электронном виде в рамках одного субъекта РФ. Цифровой профиль будет позволять хранить все документы в электронном виде с целью обеспечения возможности осуществлять проверочную деятельность и знакомиться с ними без личной явки в правоохранительные органы. На 2022 г. запланирована работа сервиса «Подача заявления в правоохранительные органы» в полном объеме в пределах предусмотренного функционального наполнения.

Однако опыт использования цифровых технологий в уголовном судопроизводстве зарубежных стран показывает, что для достижения положительных результатов внедрения передовых технологий недостаточно, необходима трансформация процессуального института, вектор назначения которой должен быть направлен на усечение излишних правовых норм, которые затрудняют его развитие, становятся дополнительной преградой на пути к его совершенствованию.

Андрей Анатольевич выразил убежденность в том, что цифровизация неизбежна, и прежде всего нужно обеспечить равный доступ всех граждан к цифровым инструментам.

Аспирант кафедры уголовно-процессуального права Университета имени О.Е. Кутафина 
(МГЮА) Татьяна Аркадьевна Топилина в докладе «Проект онлайн-сервиса для подачи заявления о преступлении» обратила внимание собравшихся на возможности электронной регистрации сообщений о преступлении.

Докладчик рассказала, что данный сервис может быть расположен на сайтах правоохранительных органов, в том числе МВД РФ и следственного комитета РФ. Возможности онлайн-сервиса предполагают, что перед подачей заявитель будет проинформирован о возможности обратиться в экстренную службу непосредственно в случае реальной опасности. Авторизацию предлагается делать через Единую систему идентификации и аутентификации государственных услуг РФ (ЕСИА). Данный сервис будет обладать функционалом информи рования заявителя о его правах, помогать ему заполнить заявление.

После заполнения всех форм заявителю будет предложено ознакомиться с уголовной ответственностью за заведомо ложный донос и сделать отметку об этом. Также сервис будет предоставлять возможность подавать ходатай- ства, жалобы на решения государственных органов, осуществляющих рассмотрение сообщения о преступлении.

Показательным Татьяна Аркадьевна назвала пример Австралии, где есть цифровые ресурсы для лиц с ограниченными возможностями, помогающие им подать заявление о преступлении посредством видео- или аудиообращения. В Российской Федерации значительное число инвалидов, и указанные ресурсы могли бы обеспечить доступ к правосудию наименее защищенных граждан.

В заключение докладчик обратила внимание на возможности подачи заявления через мобильное приложение. Оно позволяет также обратиться с сообщением о преступлении экстренно, указав место, в котором находишься. Это может быть очень полезно в случае нахождения заявителя непосредственно в ситуации опасности.

По итогам конференции участниками были обсуждены и приняты рекомендации, направленные на развитие доступа к правосудию в уголовном судопроизводстве в условиях развития цифровых технологий.

\section{РЕКОМЕНДАЦИИ \\ Всероссийской научно-практической конференции «Обеспечение доступа к правосудию в уголовном судопроизводстве в условиях развития цифровых технологий»}

22 июня 2021 г.

г. Москва

Подводя итоги научно-практической конференции, ее участники отмечают, что государством принимаются меры по обеспечению доступа к правосудию в уголовном судопроизводстве с использованием информационных технологий.

Вместе с тем необходимо понимать, что цифровизация не является целью правосудия, а лишь способствует реализации прав участников уголовного процесса и обеспечению гарантий их государственной защиты.

В целях повышения эффективности уголовно-процессуальной деятельности, создания дополнительных гарантий соблюдения прав человека в уголовном судопроизводстве участники конференции рекомендуют:

\section{Органам законодательной власти:}

1. Разработать проекты федеральных законов:

1.1. «Об электронном уголовном деле» и «О внесении изменений и дополнений в Уголовно-процессуальный кодекс Российской Федерации", предусматривающих внедрение модели ведения уголовного дела в электронном формате с возможностью фиксации проводимых процессуальных действий и принятия процессуальных решений в режиме онлайн с использованием передовых технологий (блокчейн и др.); 
1.2. «Об электронном правосудии», определяющего условия, основания и порядок осуществления процессуальной деятельности судом в электронном формате, дистанционного взаимодействия суда с населением и государственными органами.

\section{Органам исполнительной власти:}

2. Рассмотреть вопрос о создании Государственной автоматизированной системы «Доступ к правосудию», которая позволила бы автоматизировать процесс подачи и регистрации сообщения о преступлении, предполагающий создание алгоритма как системы последовательных действий заявителя о преступлении, используя онлайнсервис, включающий предупреждение об уголовной ответственности за заведомо ложный донос, подробное пошаговое описание события преступления, позволяющее его зарегистрировать как преступление, а также предусмотреть автоматическое определение подследственности по территориальному и ведомственному критериям.

3. Создать межведомственную рабочую группу с включением в ее состав представителей всех заинтересованных органов государственной власти, в том числе Верховного Суда Российской Федерации, Генеральной Прокуратуры Российской Федерации, Следственного комитета Российской Федерации, МВД России, Минюста России, Уполномоченного по правам человека в Российской Федерации, а также представителей научного сообщества для подготовки и реализации предложений, направленных на обеспечение доступа к правосудию в уголовном судопроизводстве в условиях развития цифровых технологий. 